\title{
A DIALÉTICA MICRO/MACRO NA SOCIOLOGIA DA EDUCAÇÃO
}

\author{
ZAIA BRANDÃO
}

Departamento de Educação da Pontifícia Universidade Católica do Rio de Janeiro zaia@edu.puc-rio.br

\section{RESUMO}

Neste ensaio procuro desenvolver uma argumentação a favor da superação dos monismos metodológicos no campo da pesquisa em sociologia da educação. Com base no que Jeffrey Alexander (1987) denominou o "novo movimento teórico", defendo a necessidade de superara divisão do trabalho de pesquisa entre os investigadores que se dedicam à microssociologia e os que preferem abordagens macrossociais. Nessa perspectiva, as opções teórico-metodológicas devem-se ancorar nas necessidades da investigação e não numa opção a priori do pesquisador por qualquer uma das alternativas.

SOCIOLOGIA DA EDUCAÇÃO - METODOLOGIA DA PESQUISA - PESQUISADORES

\begin{abstract}
THEMICROMACRO DIALECTIC IN THESOCIOLOGY OFEDUCATION. This article is about the micro-macro debate in sociology. Based upon the new theoretical mouvement (Alexander, 1987) it defends the linkage between those approches in the realm of Sociology of Education. In my point of view the problem and the subject of research is the anchor for the theoretical and methodological options.
\end{abstract}

Trabalho encomendado para o Grupo de Trabalho de Sociologia da Educação da Associação Nacional de Pós-Graduação e Pesquisa em Educação - ANPEd 2000. 
Mas, uma vez alcançada uma visão mais clara dos aspectos da vida social que se destacam com mais nitidez do fluxo histórico quando contemplados do alto e numa longa extensão, convém retornar à outra perspectiva, a que se tem dentro do fluxo. Cada uma dessas perspectivas, se isolada da outra, apresenta riscos específicos. Ambas - a visão aérea e a do nadador - mostramo quadro com certa simplificação. Ambas nos inclinam a depositar uma ênfase unilateral.

Norbert Elias, 1992

Uma velha polêmica atravessa a pesquisa em sociologia da educação, a divergência sobre qual a perspectiva mais compatível com o estudo dos processos educacionais: a das relações face a face entre os indivíduos empreendidas pelas análises microssociais, ou a das relações entre as estruturas (imposições) mais gerais da vida social sobre as trocas e situações mais específicas, tal como se procura alcançar com o recurso às análises macrossociais. Como problema de fundo está a questão se a ordem social se impõe como matriz que estrutura os comportamentos, ou se ela é permanentemente reconstruída pela negociação entre os indivíduos envolvidos nas ações ou trocas sociais. Subjacente ao problema está o princípio do determinismo ou da autonomia da ação social.

Nesse ensaio, tentarei traçar um panorama da constituição das tradições e escolas que fundamentam essas perspectivas concorrentes na interpretação dos fenômenos sociais, com o objetivo de defender a necessidade de superar os antagonismos teórico-metodológicos entre as abordagens micro e macrossociológicas, no campo da pesquisa em sociologia da educação.

\section{INDIVÍDUO E SOCIEDADE, A TENSÃO BÁSICA NA SOCIOLOGIA}

Em 1937, Norbert Elias escreveu um brilhante ensaio discorrendo sobre os limites das perspectivas unilaterais para apreender o fluxo do mundo social. Segundo ele, o problema maior estava na ausência de modelos conceituais que permitissem "compreender de que modo um grande número de indivíduos compõe entre si algo maior e diferente de uma coleção de indivíduos isolados" (o princípio durkheiminiano), ou seja, como se estabelecem os vínculos entre os indivíduos e a sociedade de forma a gerarem um resultado que ultrapassa as combinações iniciais.

A teoria da Gestaltjá nos oferecera um forte argumento a respeito de como o todo incorpora princípios que não podem ser delineados pelo exame das partes isoladamente. Da mesma forma que a melodia representa uma estrutura que vai além da soma das notas individuais - que há uma relação, ao mesmo tempo que 
um abismo entre os sons e as palavras - as relações entre o todo e a parte no mundo social representam um permanente desafio à inteligência pois, freqüentemente, a mudança de um plano para outro não é meramente uma mudança de grandeza ou de um ponto de vista, mas de substância ou qualidade. Um conjunto de jovens em uma sala de aula constitui uma realidade social diferente de um grupo de jovens em um coral ou em um clube.

A ordem invisível dessa forma de vida comum, que não pode ser diretamente percebida, oferece ao indivíduo uma gama mais ou menos restrita de funções ou modos de comportamento possíveis. Por nascimento ele está inserido num complexo funcional de estrutura bem definida; deve-se conformar-se a ele, moldar-se de acordo com ele [...] Até sua liberdade de escolha entre as funções preexistentes é bastante limitada. Depende largamente do ponto em que ele nasce e cresce nessa teia humana, das funções e da situação de seus pais e, em consonância com isso, da escolarização que recebe. (Elias, 1992, p.21)

Essa questão da interdependência das pessoas na teia social é longamente tratada por Elias, como uma cadeia ininterrupta de ações que associam os indivíduos em uma trama complexa de relações que os ligam a diversos grupos, os quais, por sua vez, podem ser interdependentes ou não. É esse conjunto de possibilidades de ligações, significativamente diferentes, que confere flexibilidade às relações sociais que, muitas vezes, dá a ilusão de poderem ser compreendidas na dinâmica, restrita, das relações face a face, supondo que possuem um grau de autonomia, o qual, dificilmente, podem alcançar. O comportamento dos alunos em uma turma, uma escola ou em um sistema escolar certamente pode ser analisado em sua relativa autonomia em cada uma dessas instâncias; entretanto, nenhuma turma, escola ou sistema abriga qualquer aluno aleatoriamente: a probabilidade de as turmas de determinadas escolas serem compostas por qualquer estudante de uma determinada faixa etária é decisivamente descartada'. Crianças e jovens moradores de Jacarepaguá (município do Rio de Janeiro) só excepcionalmente estudarão em Caxias (periferia do mesmo município), assim como filhos de grandes empresários dificilmente estarão matriculados em uma escola municipal mal equipada. São essas conformações mais estruturais - por exemplo, a distribuição demográfica da população em uma área específica - que indicam o caráter definidor de algumas circunstâncias macrossociais sobre interações microssociais.

I. O desenvolvimento de modelos multiníveis de análise estatística significou um avanço importante nas estatísticas educacionais na medida em que permitiram contemplar a característica estratificada da demografia escolar. 


\section{AS BASES EPISTEMOLÓGICAS DAS ORTODOXIAS E SUA SUPERAÇÃO}

Qual o melhor observatório do mundo social: a perspectiva próxima e de "dentro" ou a perspectiva panorâmica, do alto e de "fora da cena"? O mundo pensado como um teatro: o teatro reproduzindo as matrizes de convivência, ou criando permanentemente novas formas de interagir? O mundo social como improviso permanente, surpreendente e incomensurável, ou como um enredo definido pelas posições anteriormente ocupadas pelos atores, diretores, fotógrafos e cenaristas? O cenário enquadrando a cena, ou o enredo exigindo a multiplicidade de cenários?

Vivemos nestas últimas décadas uma desconfiança saudável das ciências sociais como racionalizações sobre o mundo empírico (o da experiência). Tais racionalizações produziram tanto grandes ilusões como admiráveis tomadas de cena. A pergunta que se mantém pertinente é sobre qual instância privilegiada para a compreensão do que somos socialmente, dos sentidos das nossas ações e dos significados que elas produzem. Eis o permanente dilema epistemológico que nos é apresentado pelas ciências sociais (Alexander, 1987, cap. 3).

O problema teórico da tensão subjetivismo/objetivismo, agentes/estruturas durante muito tempo esteve ancorado em perspectivas epistemológicas antagônicas. Hoje, as novas sociologias (Corcuff, 1995) ou o novo movimento teórico(Alexander, 1987) tendem a superar essas oposições clássicas e defender que o coletivo é individual e que os níveis microssociais constroem gradativamente padrões de ações e representações que se consubstanciam em estruturas de níveis macrossociais.

Essas novas sociologias propõem perspectivas teóricas que podem elucidar tanto os processos que vão das estruturas sociais às interações, como os que vão das interações às estruturas sociais. Entretanto, duas posições epistemológicas polares coexistem como permanente desafio à imaginação sociológica:

- uma, que privilegia o olhar sobre a reprodução dos papéis e posições sociais herdadas do passado e presentes no mundo social, sustentando a pretensão de construir teorias mais gerais sobre as regularidades das relações sociais. Normalmente focaliza as bases em que se sustentam determinadas práticas sociais que, pela recorrência nas situações cotidianas, transformam-se em disposições - as quais se situam e agem de acordo com as posições sociais definidas pelas estruturas sociais (empregados/ empregadores, intelectuais/massa, femininas/masculinas) -, agregando subconjuntos de agentes, relativamente estáveis, que podem ser reconstruídos no plano macrossocial; 
- outra que, supondo a incomensurabilidade do social, descarta as tentativas de teorização mais geral sobre a sociedade, e procura construir hipóteses, a partir dos fragmentos microssociais, sobre a dinâmica do(s) mundo(s) social(ais); algumas vezes chega até mesmo a afirmar ser o mundo social uma permanente ilusão constituída pela recriação de papéis e situações, a partir das interpretações forjadas nas interações face a face e pela linguagem. Não haveria pois por que investir em teorias mais gerais sobre o mundo social. Tudo o que se poderia aspirar é um conjunto de interpretações subjetivas e ilusórias do ponto de vista do mundo da experiência.

\section{O NOVO MOVIMENTO TEÓRICO SEGUNDO JEFFREY C. ALEXANDER}

Jeffrey C. Alexander, um dos mais importantes sociólogos americanos da atualidade, assinala a importância da argumentação na elaboração teórica nas ciências sociais, pois, em virtude do seu caráter multiparadigmático, elas se encontram divididas em escolas e tradições, expressando um desacordo teórico-empírico permanente. É com base na argumentação que se articulariam as adesões e convicções a respeito da pertinência de determinadas opções analíticas no âmbito das ciências sociais.

Depois da Segunda Guerra - em virtude do insucesso da tentativa parsoniana de compatibilizar o idealismo e o materialismo, a ação voluntária e a determinação estrutural - instalou-se, segundo o autor, um movimento pendular entre as teorias da ação e as teorias estruturais. Surgiram, então, reações de raízes fenomenológicas e estruturalistas indicando os dilemas teóricos sobre a natureza da ação e da ordem.

Sob a inspiração fenomenológica multiplicaram-se as perspectivas microssociais:

- para a teoria das trocas (Homans) o comportamento individual desenvolve-se independentemente de normas sociais definitivas, pois as condições sociais objetivas articulam-se à vida cotidiana, produzindo situações a partir das quais os atores desenvolvem os seus cálculos e orientam suas ações no mundo social;

- no interacionismo simbólico (Blumer) os significados resultam das relações sociais que se estabelecem em cada circunstância (em razão das reações do outro), e o que define as atitudes são as imagens, significados, sinais e linguagens que interagem na definição das situações em que se encontram os atores sociais; Goffman, dentro dessa orientação, desen- 
volveu uma abordagem teórico-metodológica de observações diretas e elaboração de conceitos, inspirado na dramaturgia, que permitiu o desenvolvimento de uma perspectiva sociológica bastante adequada à interpretação de processos de comportamento institucional gerados a partir de interações face a face;

- a etnometodologia (Garfinkel) desenvolveu-se a partir de uma inovação metodológica (etnometodologia) que se pretendia mais adequada ao conhecimento de como os atores constroem suas próprias normas em situações (culturais) específicas do cotidiano e com o recurso à linguagem.

Entre os defensores de perspectivas macrossociais estão os "teóricos do conflito" - que negam a centralidade da internalização das normas (elo entre ação e cultura) tal como proposta pelo estrutural-funcionalismo parsoniano - e as perspectivas funcionalistas, sistêmicas e estruturalistas de diferentes extrações teórico-ideológicas.

Segundo Alexander (1987), um "novo movimento teórico" engloba uma nova geração, pós-marxista (e pós-funcionalista, acrescentaria eu), que influenciada pela microteoria norte-americana desenvolveu novos esforços de juntar ação e estrutura. A consciência da complexidade dos processos envolvidos nas relações e transformações sociais estimulou, mais recentemente, tentativas de ligar os planos micro e macrossociais, assim como os processos individuais ao sistema social mais amplo. A percepção do papel central da cultura na constituição do mundo social motivou o renascimento dos estudos culturais iniciados nos anos 60 (Birmingham) e uma ênfase crescente no estudo das estruturas simbólicas e das representações sociais.

\section{AS TRADIÇÕES NA SOCIOLOGIA DA EDUCAÇÃO NO BRASIL}

Em que pese a já assinalada sociologização do discurso pedagógico, ainda não contamos com um balanço histórico que nos permita reconstituir, de forma consistente, as tendências micro e macroteóricas na sociologia da educação no Brasil. Entretanto, um sobrevôo sobre a produção relacionada explicitamente à sociologia da educação autoriza-nos a algumas hipóteses que traçaremos a seguir.

A pesquisa em educação recebeu um enorme impulso após a institucionalização da pós-graduação. Como de uma forma geral ocorreu com o desenvolvimento das Ciências Humanas, os parâmetros de cientificidade positivista marcaram inicialmente a importância da quantificação e das teorizações gerais. Só com o de- 
senvolvimento da autonomia do campo é que, gradativamente, outras referências e estratégias foram sendo incorporadas à produção de pesquisas em educação.

Uma antologia organizada por Luiz Pereira e Maria Alice Foracchi, no início nos anos 60 - Educação e sociedade: leituras em sociologia da educação -, coloca em evidência a hegemonia das perspectivas macrossociais àquela época. A maioria dos textos da coletânea refere-se aos processos sociais globais, focalizando as funções sociais da escola - homogeneizadora/diferenciadora, inovadora/conservadora assim como os processos de estratificação social, burocratização e planejamento. A relação entre a educação e a estrutura social é tratada nos estudos das sociedades tradicionalistas e das sociedades de classes, assim como na análise - atualíssima na época - das relações entre a educação escolar e o desenvolvimento econômicosocial. Mesmo quando se referem ao estudo sociológico da escola (parte III) os organizadores assinalam que o tratamento deste tema

... não significa contudo (que) deva ser encarado como uma unidade autônoma, ou que a análise seja, necessariamente, limitada aos aspectos internos da escola. Pelo contrário, é da maior importância compreender a dinâmica do grupo escola através das conexões que estabelece com outros sistemas sociais, de amplitude variável. (Pereira, Foracchi, 1969, p. I01, grifos meus)

A investigação desenvolvida durante quatro anos, sob a minha coordenação, focalizando a sociologia da educação nos anos 50/60, identificou, no entanto, uma influência da tradição microssociológica da Escola de Chicago em pesquisas desenvolvidas no Centro Brasileiro de Pesquisas Educacionais - CBPE - e publicadas nos seis anos de existência (1956/1962) da revista Educação e Ciências Sociais². Entretanto, o fechamento do centro e o sucesso dos paradigmas "críticos"3 parecem ter desmobilizado essa tradição, na pesquisa sociológica no campo da educação, que parece ter permanecido esquecida ${ }^{4}$ durante cerca de duas décadas (Brandão, Mendonça, 1997).

2. Conferir, a respeito, em especial o capítulo de autoria de Libânia Nacif Xavier "A pesquisa do CBPE em Revista" (Brandão, Mendonça, 1997).

3. Utilizo o termo de modo impreciso para indicar o conjunto de teorias que criticavam os desdobramentos sobre a escola das estruturas capitalistas e, sobretudo, para evitar a categorização equivocada de teorias reprodutivistas englobando autores tão diferentes em seus fundamentos como Althusser, Bourdieu e Passeron, Bowles e Gintis, Baudelot e Establet. Ver, a respeito, Cunha (1992)

4. A expressão tradição esquecida, utilizada no título do livro, refere-se ao projeto liderado por Anísio Teixeira de articular cientistas sociais e educadores com a criação do CBPE, assim como dos centros regionais a ele articulados. 
A sociologia da educação, nas décadas de 60 e 70, no Brasil, caracteriza-se por uma produção voltada para o espelhamento da estratificação social na estrutura do sistema escolar. Desde o final da década de 50 Anísio Teixeira, Florestan Fernandes, J. Roberto Moreira, entre outros, utilizavam-se amplamente de dados demográficos e indicadores socioeconômicos para interpretar o caráter antidemocrático da escola brasileira, sempre em uma perspectiva macrossocial.

A politização das universidades, provocada pela luta contra o regime militar implantado pelo golpe de Estado de 1964, foi responsável pela retração da pesquisa na área da sociologia da educação e pela proliferação de uma produção de caráter mais ensaístico e teórico, que buscava contrapor-se "à ênfase na administração e no planejamento educacionais ao lado da supervalorização da tecnologia educacional" (Cunha, 1992).

No âmbito da sociologia da educação, entretanto, a obra de maior impacto, na perspectiva macroteórica, foi Educação e Desenvolvimento Social no Brasil(Cunha, 1975). Cunha trabalha simultaneamente dados e indicadores econômicos e educacionais para contestar a tese de Carlos Langoni de que a concentração de renda no período militar teria ocorrido por deficiências de escolarização da população. Numa análise inspirada, entre outros, na perspectiva de Bourdieu e Passeron, traça um quadro dos mais completos sobre as características da escola brasileira e da política educacional implantada pelo regime militar a partir do final da década de 60 .

Um dos mais importantes periódicos de pesquisa em educação - Cadernos de Pesquisa (publicado desde 197I pelo Departamento de Pesquisas Educacionais da Fundação Carlos Chagas) - reflete a importância das pesquisas que se utilizavam de dados quantitativos e das abordagens de caráter macrossocial. Ana Maria Poppovic, Fúlvia Rosemberg, Bernardete Gatti, Guiomar Namo de Mello, Heraldo Vianna, entre outros, eram pesquisadores daquela instituição que se utilizavam de dados sociodemográficos nas investigações sobre educação, numa perspectiva sistêmica e macrossocial, em suas interpretações sobre os fenômenos da alfabetização, educação fundamental, marginalidade cultural e da desigualdade escolar em vários níveis.

Em 1982, o Instituto Nacional de Estudos Pedagógicos - Inep - encomendou-nos o primeiro estado da arte sobre a evasão e repetência no Brasil (Brandão, Baeta, Rocha, 1982), no qual ainda utilizamos as famosas pirâmides educacionais na análise das estatísticas oficiais ${ }^{5}$; entretanto, já nessa ocasião, privilegiamos algumas poucas pesquisas, de caráter qualitativo, que começavam a ampliar o escopo das

5. O modelo Pró-Fluxo, desenvolvido na década de 80 por Costa Ribeiro e equipe, contestou os modelos estatísticos utilizados pela Seec/MEC, sobre os quais eram geradas as pirâmides 
análises sobre os problemas de desempenho escolar com base em focalizações microssociais. Cabe assinalar ainda que, naquele momento, já manifestávamos o nosso interesse por uma perspectiva que, mesmo mediante estratégias qualitativas de análise, articulasse aspectos macro aos microssociais:

...um novo prisma de análise, que somente desponta no horizonte da pesquisa educacional e, ainda assim, com alcance muito restrito: falamos de uma perspectiva de análise que incorpora o contexto socioeconômico e político de forma menos fatalista e que procura dentro da escola o que the é específico, sem descuidar nem do indivíduo nem do social, mas procurando incorporar a categoria "totalidade" na análise da prática escolar. (Idem, p. 12)

Com a chegada da década de 80, portanto, a crítica ao positivismo e ao caráter demasiadamente genérico das enquetes estatísticas (surveys) - distantes dos problemas das escolas e das salas de aula - provocou uma virada hegemônica no campo das estratégias metodológicas na sociologia da educação. Os estudos de caso, a observação participante e as estratégias de pesquisa qualitativa foram gradativamente dominando a pesquisa em educação. Essa mudança ocorreu com tal ênfase nessas duas últimas décadas que, em determinados fóruns, a presença de estatísticas educacionais passou a ser associada, com boa dose de preconceito, aos

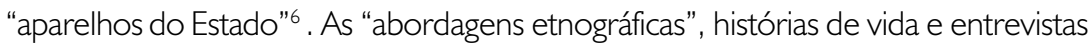
em profundidade tornaram-se os recursos preferenciais das abordagens microssociais que, ainda, neste final de década, dominam a pesquisa na sociologia da educação. Porém diferentemente da expectativa que expressávamos em 82, a proliferação dessas abordagens indica que o "novo movimento teórico" de articulação entre as perspectivas macro e micro, a que se referiu Alexander (1987), não encontrou muitos adeptos entre nós.

Entretanto, rediscutir a avaliação educacional impulsionada quer pelas políticas neoliberais, quer pelas estratégias de aprofundamento das políticas de democratização - como a institucionalização dos ciclos escolares ou a promoção automática trouxe um novo impulso às análises macrossociais e ao recurso às estatísticas para a

educacionais; estas, segundo ele, indicavam taxas de evasão escolar muito superiores às encontradas pela nova metodologia. Hoje as pirâmides não fazem mais parte dos gráficos das estatísticas escolares oficiais.

6. Na última Reunião Anual da ANPEd, de 1999, presenciei um debate com Alceu Ferrari, em que o interlocutor questionava a análise do pesquisador gaúcho sobre alfabetização, com o argumento de que ele estaria utilizando estatísticas da Fundação Instituto Brasileiro de Geografia e Estatística - FIBGE - e, portanto, dados do governo que não mereceriam confiança. 
caracterização, análise e interpretação dos sistemas escolares em suas relações internas (subsistemas estaduais, municipais, privados etc.) e externas (perfis familiares, características socioculturais dos professores, categorias socioprofissionais das populações etc.).

Tudo indica que a ligação dos níveis macro e microssocial tem-se tornado um horizonte cada vez mais atraente para aqueles que tomam consciência da inextrincável complexidade do mundo social e, nele, da educação. Que ordem de problemas nos colocam tais ligações?

\section{DA REDUÇÃO À LIGAÇÃO: SUPERANDO OS MONISMOS METODOLÓGICOS}

O problema da ligação (micro macro) está na capacidade de criação de conceitos teóricos que traduzam ou reinscrevam variáveis de nivel individual em variáveis que caracterizem os sistemas sociais e vice-versa.

Gerstein, 1987

Os problemas da ligação micro/macro surgem sempre que o menor liga-se ao maior ou vice-versa; "maior-menor, parte-todo são instrumentos culturais de pensamento com os quais a sociologia partilha da experiência humana" (Gerstein, 1987, p. 109). Gerstein propõe "quatro princípios" para entender essas relações:

- reconhecer que a ação social é inerentemente dual, ou seja, pode ser representada por escalas assim como exprimir-se por significados, e que essas dimensões não funcionam da mesma forma. Uma análise da ação social deve encontrar o recurso adequado para a sua compreensão, tanto no plano da estatística, como da interpretação; a distinção micro/macro atravessa a dualidade quantitativo/qualitativo perpendicularmente e não paralelamente;

- a distinção fundamental entre micro/macro deve ser analítica. As designações são sempre de caráter relativo entre os níveis e, em particular, ao propósito analítico do momento;

- a natureza causal da ligação macro/micro não deve ser postulada em princípio. Deve sempre ser considerada hipotética e incompleta. As posições que defendem causas inerentemente macro ou micro tendem ao reducionismo; igualmente equivocadas estariam as alternativas relativistas 
que postulam que os planos micro e macro são inteiramente autônomos. Parece mais adequado postular um potencial interativo entre os níveis micro e macro com graus variáveis no tempo e sob diferentes condições;

- o uso habitual e bem-sucedido de uma das perspectivas pode levar a posições de fidelidade teórica a determinadas escolas de pensamento ou abordagens teórico-metodológicas; a competição entre opções preferenciais nestes âmbitos pode ser útil à produção do conhecimento, desde que propicie um debate produtivo, do ponto de vista do aperfeiçoamento ou aprofundamento das condições de compreensão dos fenômenos estudados.

As novas sociologias (Corcuff, 1995) rejeitam as perspectivas unilaterais pois os processos e configurações (estruturas) sociais estão inseparavelmente ligados às dinâmicas micro e macrossociais:

- o nível micro envolve normalmente um pequeno número de atores que têm a possibilidade de observar-se mutuamente. A interação face a face caracteriza esse nível: pessoas, ações, padrões de comportamento e aspectos específicos da situação são passíveis de serem observados em sua totalidade. Na prática de pesquisa, no entanto, os pesquisadores reduzem sua atenção a determinados aspectos da cena social;

- o nível macro envolve sempre muitos atores que não estão em interação direta. O pesquisador consegue observar apenas indicadores e representações do conjunto das ocorrências, que devem ser novamente traduzidos em hipóteses (interpretações) sobre as ações subjacentes a essas referências (Haferkamp, 1987, p. 178).

As ações podem ser significativas ou expressar comportamentos não intencionais; as abordagens qualitativas nem sempre estão alertas para a possibilidade de que muitas das situações e significados não encontrem, nos atores diretamente envolvidos, a melhor referência para a sua interpretação. As posições no espaço social, as experiências anteriores, os diferentes contextos institucionais etc. podem vir a ser indicadores mais adequados à compreensão de determinadas práticas e representações do que os depoimentos ou observações dos agentes sociais envolvidos diretamente nas ações/situações.

As transcrições "fiéis" de depoimentos podem portanto carecer de fidedignidade no processo de construção interpretativa por parte do pesquisador. Elas po- 
dem significar o mesmo equívoco das "transcrições teóricas" no trabalho de campo, ou seja: da mesma forma que as referências teóricas precisam ser reelaboradas no processo de investigação (construção do objeto), os depoimentos obtidos por meio de entrevistas precisam ser novamente situados no contexto geral das circunstâncias investigadas - implicados aí tanto o problema que orienta a pesquisa, como as relações dentro das quais o objeto em estudo vem sendo construído e os contextos (materiais e simbólicos) em que se desenvolvem. Os significados que os atores atribuem às suas ações não são autocriados; além de operarem na complexa malha das representações de sua cultura, estão articulados às conjunturas específicas, às configurações espaço-temporais que os localizam nas estruturas sociais, aspectos esses nem sempre imediatamente percebidos pelos atores sociais ou pelos pesquisadores.

O poder, material e simbólico, pode promover padrões de submissão incompreensíveis tanto para os que o exercem como para os que a ele são submetidos. Haferkamp, ao desenvolver uma crítica à atenção exclusiva conferida à definição verbal da situação, assinala a importância de reconhecer que a ação social é composta de elementos verbais e não verbais, e que eles não são redutíveis um ao outro; como as situações sociais são complexamente estratificadas e finamente estruturadas, se focalizarmos apenas a definição verbal da situação, teremos uma abordagem simplificada da ação (idem, p. 182).

É importante ainda destacar que o simples fato de as estruturas não serem passíveis de observação direta não significa que sejam inacessíveis ao conhecimento. Há, portanto, necessidade de incluir tanto os aspectos subjetivos quanto os processos externos na elaboração, análise e interpretação das pesquisas em ciências sociais.

É uma ilusão imaginar que a multiplicação de análises microssociais permitiria uma forma mais adequada de reconstrução das configurações sociais gerais (estruturais), ou que se poderiam alcançar essas configurações pela reconstrução diversificada e ampliada das configurações particulares. $\bigcirc$ mundo da experiência tem uma capacidade inesgotável de recriar e construir novas formas de interações e padrões coletivos de valores que se desdobram em ações significativas complexas no plano individual (interações face a face) e no plano macrossocial. A arte do pesquisador, ao que nos parece, estaria exatamente em sua capacidade de escolher o instrumento de análise mais adequado ao problema de pesquisa que o desafia e às possibilidades empíricas do campo de investigação em que se coloca. 


\section{REFERÊNCIAS BIBLIOGRÁFICAS}

ALEXANDER, J. O Novo movimento teórico. Revista Brasileira de Ciências Sociais, v. 2, n. 4, p. 5-28, jun. 1987.

BRANDÃO, Z.; MENDONÇA, A. W. P. Uma tradição esquecida: por que não lemos Anísio Teixeira? Rio de Janeiro: Ravil, 1997.

BRANDÃO, Z.; BAETA, A.; ROCHA, A. C. Evasão e repetência no Brasil: a escola em questão. Rio de Janeiro: Achiamé, 1982.

COLEMAN. J. S. Microfoundations and macrosocial behavior. In: ALEXANDER, J. C., et al. (eds.). The Micro-macro link. California: University of California Press, 1987.

CORCUFF, P. Les Nouvelles sociologies. Paris: Nathan, 1995.

CUNHA, L. A. Educação e desenvolvimento social no Brasil. Rio de Janeiro: Francisco Alves, 1975. 1992.

. Educação na sociologia: um objeto rejeitado? Cadernos CEDES, n. 27, p. 9-22,

ELIAS, N. A Sociedade dos indivíduos. Rio de Janeiro: Zahar, 1992.

GERSTEIN, D. R. To unpack micro and macro: link small with large and part and whole. In: ALEXANDER, J. C. et al. (eds.). The Micro-macro link. California: University of California Press, 1987.

HAFERKAMP, $\mathrm{H}$. Complexity and behavior structure, planned associations and creaton of structure. In: ALEXANDER, J. C. et al. (ed.) The Micro-macro link. California: University of California Press,. 1987. p. 177-92.

PEREIRA, L.; FORACCHI, M. Educação e sociedade: leituras em sociologia da educação. 4. ed. São Paulo: Nacional, 1969.

XAVIER, L. A Pesquisa do CBPE em revista. In: BRANDÃO, Z., MENDONÇA, A. W. Uma tradição esquecida: por que não lemos Anísio Teixeira? Rio de Janeiro: Ravil, 1997. p. $83-139$. 